\title{
A PROPOSAL FOR GREEN PLANNING IN CITIES
}

\author{
F. GOMEZ ${ }^{1} \&$ P. SALVADOR ${ }^{2}$ \\ ${ }^{1}$ Department of Architectonics Constructions, Architecture School, Polytechnic University of Valencia, Spain. \\ ${ }^{2}$ Valencia Council, Green Planning Office, Valencia, Spain.
}

\begin{abstract}
Many international institutions are developing pilot projects in different cities of the European Community to demonstrate the benefits obtained from green plans and action programs. In this way they intend to encourage local authorities to analyze the amount of land devoted to green zones and extend green zones whenever possible. The purpose of a 'Green Plan' is not that of urban planning neither is it a simple system of green zone planning in cities. It consists of a complementary and parallel approach to urban planning based on multidisciplinary teams formed by rural and urban experts, and also based on an ethical platform far from utilitarianism that enhances people's welfare. A Green Plan represents the paradigm of the concept of sustainable development: it can contribute to integration in terms of natural harmony, beauty, life quality and health. In this work we examine the role of green planning in cities and analyze the proposal of the Green Plan for the city of Valencia. We also suggest the Green Plan of Valencia as a research model for green planning.

Keywords: green planning, green zones, urban climate, urban comfort, Valencia (Spain).
\end{abstract}

\section{INTRODUCTION}

Today cities exert an increasing attraction on people worldwide; in fact, the population tends to concentrate in big cities. In the 21 st century the number of people living in cities will progressively increase. As can be seen in Table 1, the percentage of the urban population has increased dramatically.

It is a fact that urban planning is experiencing a crisis; at least the concept of urban planning that appeared with the Modern Movement and its myriad of architects. To understand the meaning of this statement let us recall the following quotation: 'Anyone who visits Brasilia will notice with horror the kind of urban planning developed by Le Corbusier, whose style is noticeable in the external districts of the city with those large avenues. The monumentality of Brasilia prevents social life, enjoying street walks or meetings at the agora, i.e. it is anti-community. It is also cold, superficial, mechanical, colossal; it represents the materialization of the problems of industrial mechanicism, anemia, segmentation, loss of human quality, dominance of the machine over man' [2].

In this sense, there are many authors who consider that the old concepts of urban planning need to be revised to adapt them to new developments and ideas. The basis of the urban crisis lies in the dimensions and expansion of the large cities where these problems become even more severe.

The urban phenomenon is continuously increasing, extending the boundaries of the city or metropolitan area. Some indicators and experts' opinions indicate a lower index of urban planning than expected by the United Nations. However, the reality in the big cities presents a number of problems that are worth mentioning. The invasion of periurban spaces causes the loss of land, natural resources and landscape.

Urban cities occupy only a small part of the territory; actually cities occupy only $2 \%$ of the surface area of the territory. However, each city has its own history, marked by the way it extended and grew; thus it is not surprising to find cities that expanded and occupied new land even in periods in which the population was decreasing [3]. However, although the surface area occupied by the city is relatively small, it is the urban segment that presents more of a threat to the rest of the land.

The city has never taken the periurban spaces, i.e. the nonurbanizable land, into consideration. Egocentric urban planning pays little attention to the city surroundings. Therefore, to complement 
Table 1: Percentage of population in urban areas [1].

\begin{tabular}{lcccc}
\hline Years & 1950 & 1975 & 2000 & 2030 \\
\hline World total (\%) & 29.8 & 37.9 & 47.2 & 60.2 \\
Highly developed regions (\%) & 54.9 & 70.0 & 75.4 & 82.6 \\
Developing regions (\%) & 17.8 & 26.8 & 40.4 & 56.4 \\
North America (\%) & 63.9 & 73.8 & 77.4 & 84.5 \\
Latin America and Caribbean (\%) & 41.9 & 61.4 & 75.4 & 84.0 \\
Oceania (\%) & 61.6 & 72.2 & 74.1 & 77.3 \\
Europe (\%) & 52.4 & 67.3 & 73.4 & 80.5 \\
Asia (\%) & 17.4 & 24.7 & 37.5 & 54.1 \\
Africa (\%) & 14.7 & 25.2 & 37.2 & 52.9 \\
World total (million inhabitants) & 2520 & 4070 & 6060 & 8270 \\
\hline
\end{tabular}

this green planning is required and necessary; green planning provides the complementary land planning to urban planning as it also covers the surrounding land of the city.

One of the key issues for better urban planning is the creation of green zones in cities. In this sense, green zones constitute one of the basic parameters of sustainability included in the different indicators developed worldwide. Among the existing indicators we can mention the First Generation of Common European Indicators, developed by the Expertise Group on Urban Environments of the EU General Directorate for the Environment. According to the technical report, the existence of public green zones is among the five main indicators of sustainable European cities [4].

It has been proved that green zones not only play an important role as ornamental or landscaping factors but also enhance people's well being and improve the climatic conditions of cities by acting as coolers or regulators in the exchange of air and temperature [5]; urban vegetation is particularly beneficial, improving urban comfort [6] and reducing the heat-island effects [7], an effect that is evident as a consequence of the vegetation on the balconies of buildings [8].

However, the most significant role of vegetation, particularly in warm regions, is the control of luminosity and solar radiation, preventing solar radiation from reaching paved surfaces which accumulate heat.

\section{OBJECTIVES}

This work focuses on the analysis of 'green planning', which involves a rigorous, detailed and local analysis of the city in order to avoid general formulations. In other words, the purpose of this study is to analyze the main problems in cities, and where, when, under which circumstances and to what extent these problems occur.

Based on a detailed analysis of all the factors that intervene in the process it will be possible to gain an overall view of the situation including the physical aspects of the city and the life quality of its citizens.

The first part of this work analyzes the technical team in charge of the development of the research work, and describes the task involved in green planning.

The second part of this work refers to a particular aspect of green planning, probably the most important aspect, namely Urban Green Planning. The main objective of the second part is: understanding the meaning of the meteorological variables affecting cities, which are used in the development of different comfort indices by different authors from which we have selected the most relevant indices 
for this particular study. To that end, the comfort indices selected have been applied to the city of Valencia and the results have been compared to a real bioclimatic characterization of the city.

Finally, following the criteria given by the authors of the comfort indices in terms of the environmental parameters used $[9,10]$, we relate them to the existing green zones in the city in order to analyze the influence of the green areas on urban microclimate and, as a consequence, on human comfort.

The final goal of this work is to obtain a suitable formulation of the comfort indices for the city of Valencia in terms of the green zones existing in the city, and to formulate a comfort index that allows the quantification of the green zones. That is, to provide city planners with a methodology that allows them to know the amount and the location of the green zones in order to create a more comfortable city.

The use of comfort indices that include the effects caused by urban green zones is based on the well-known fact that the presence of vegetation in cities alters the energetic balance of the local climates causing variations in the solar radiation reaching the ground [11], wind flows, environmental temperature and air humidity [12].

These effects, though limited, contribute significantly to improve comfort perception in urban open spaces.

\section{BACKGROUND}

The first reflections on the deficiencies and excesses of cities and, as a consequence, on the need for some sort of compensation come from the well-known designers Frederick Law Olmsted and De Stein, with their important works of Central Park, in New York (Manhattan, 1866; Fig. 1), and with the big complex of the Parkways in Boston (1906). The beginning of the 20th century saw the start of the movement of the beautiful cities and the Chicago Fair, based on the model of city-garden and hygienism.

The recommendations of the 1st International Congress on Hygiene and Urban Problems held in Paris (1900), which evolved during the same period, are similar in nature. These recommendations established that cities like Paris and London should have 10\% of their urban area devoted to parks and green zones. A few years later, in 1907, this percentage was increased at the 2nd International Congress.

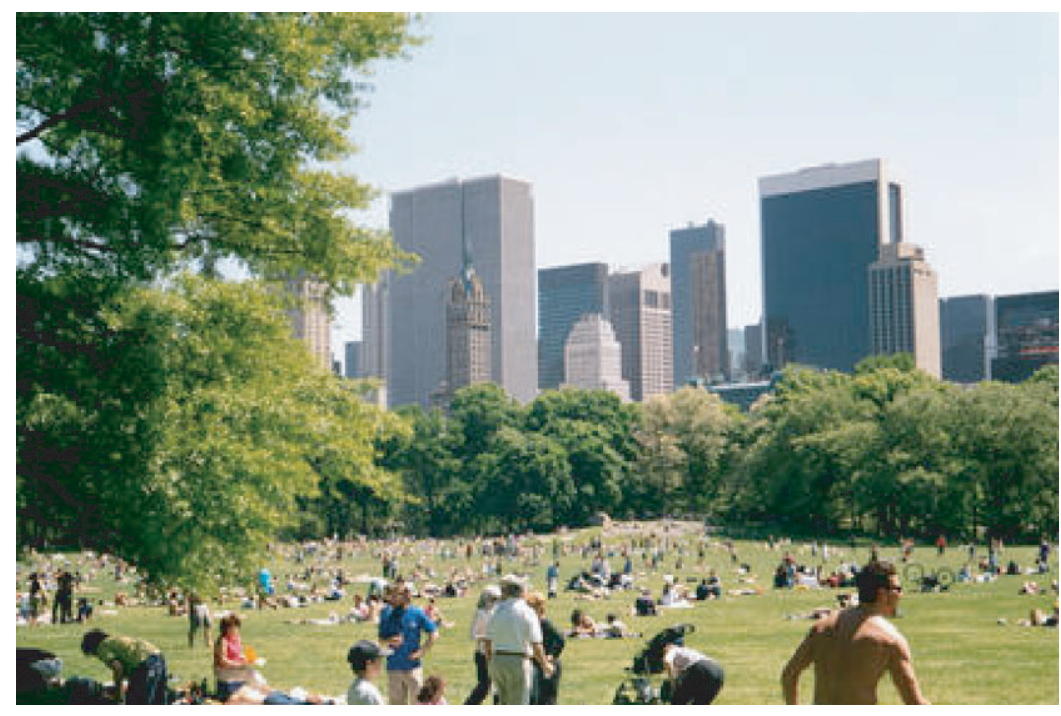

Figure 1: Central Park in New York. Urban park with 320 ha in the center of the city. 
In 1932 the Athens Chart was elaborated as a result of the work developed during the International Congress on Architecture held in Athens. This Chart established the principles of functionalism and of an 'international style' in architecture and urban planning. The two principles of functionalism led to urban planning by 'zoning', whose speculative practical application resulted in the dramatic reduction of green spaces. Today this concept has been seriously questioned as the functional model has shown its limitations and lack of flexibility to adapt to underdeveloped regions or to activities close to marginality or unemployment.

Concurrent with the evolution of the principles of functionalism a new and growing interest in nature emerged, particularly in the Anglo-Saxon countries, thanks to people like Thijsse in Holland, who developed the Development Plan of Amsterdam in 1935 (one of the first General Urban Plans), and to the Natural Conservancy Council, created in the United Kingdom in 1949.

In the 1970s ecology emerged as a distinct field in Europe and USA. One of the events that contributed to its emergence was the approval of the NEPA (National Environment Policy Act) in 1969 in the United States, the first powerful law in the defense of the environment. It also involved a new concept of design (Design with Nature, by Ian McHarg, 1969).

Other relevant events were the 1st International Congress on Ecology, held in The Hague (1974), and the work of the Dutch pioneers Le Roy, Van Leeuwn and Ruff, and English authors such as Nicholson, with their theories on ecological urban planning and landscaping ecology, promoted at the renowned Urban Planning School of Delft (Holland).

An important fact was the development of the MaB (Man and Biosphere) program by the UNESCO in 1971, which provided a new approach: the concept of man as the main actor interacting with the physical and biological environment (the biosphere). In particular, MaB-11 was concerned with the integration of ecological studies in urban systems as a basis for urban planning and management. In 1972 the Conference of the United Nations on Human Environment, held in Stockholm, emphasized people's right to have a healthy and productive environment.

In 1990 the Commission of European Communities published its Green Paper on Urban Environment [4]. This document was a touch of attention to city authorities by the highest European body; though the document had no competence in urban issues and despite the controversy it raised, the document was legitimized by the concern that the European citizens were transmitting to their own local authorities. This document contains direct references to the convenience of developing and implementing green plans in European cities.

The European Unique Act in 1986, and the Maastricht Treaty of the European Union in 1992, incorporated some additional paragraphs to Article 130.R. Of particular relevance is the following paragraph: 'the need for the protection of the environment should be integrated in the definition and implementation of the other policies of the Community'. In particular, the Maastricht Treaty, in its Article 130.L.1., considers measures related to land planning, land use and the management of water resources.

Programme V of Policy and Action on the Environment and Sustainable Development (European Union, 1993) emphasized the general concern about the environment and pointed out the new aspects of the Treaty of the Union, confirming some of the aspects defined by the Bruntland Committee and reinforcing principles such as subsidiarity or issues related to poor management policies or imbalances.

\section{CONTENTS OF GREEN PLANNING}

The philosophy and contents of the Green Paper on Urban Environment [13] considers green planning as a revision of the principles and practices in urban planning, introducing positive components and environmental, ecological and landscaping constraints. Obviously, these digressions have a general 
meaning and each city should try to solve its problems depending on the needs and demands of its population. The diagnosis following the stages of understanding and analysis is the first approach for a critical vision, i.e. the starting point of a green plan. This is the meaning of the principle of subsidiarity promoted by the European Union, i.e. the solutions provided by the authorities closer to the users.

The lack of guidelines about nonurbanizable land in the official urban plans makes it necessary to include all the factors. It is important to analyze rigorously the kind of activities to develop at the border or interface areas to the urban-rural lands, due to the consequences derived from these actions, and to establish effective technical control mechanisms of environmental or landscaping impact.

From the point of view of impact studies, the excesses of urban growth should be corrected, the rural and natural values should be protected and promoted, and a wide, varied and linked net of green spaces and relation spaces (e.g. crossings) should be enhanced. A joint formulation and collaboration of the infrastructure plans and projects or industrial actions will allow the introduction of qualitative proposals compatible with the environment and the landscape (Fig. 2).

The basis and economic behavior of the territory are also fundamental aspects for green planning, at least from the structural point of view. Certain environmental problems generate costs and losses of time and land, and marginality in some areas. We are dealing with a fragile relationship between ecology and economy, which is neither opposite nor presents a direct relationship, but they both move in a common set of balances and compensations. As stated by the Commission for European Land Planning [14]: '[...] sustainability is not only a mere environmental concept, but it can be applied to all human activities. Economy and Ecology become the two sides of the same coin.'

The objectives of green planning tend to rebalance urban issues, to stop mercantile or industrial expansion and urban congestion or uncontrolled dispersion of the habitat, and also contribute to preservation of open spaces and natural zones.

This is not hygienist content, although it emphasizes the real interest in life quality and health of the citizen; and neither is it a hedonist approach, but in it underlies the ideas of climatic comfort, psychophysiologic comfort and ecologic balance. Breheny [15] defines green planning as 'planning for environmental capacity'.

A vision of the future must integrate the city, nature and the landscape; we find an illustration of this in the project of Ecoville in Toronto or, many centuries ago, at the beginning of the Rennaissance, in Bonfadio's dream, the terza natura, by the Lake of Garda [16] (Fig. 3).

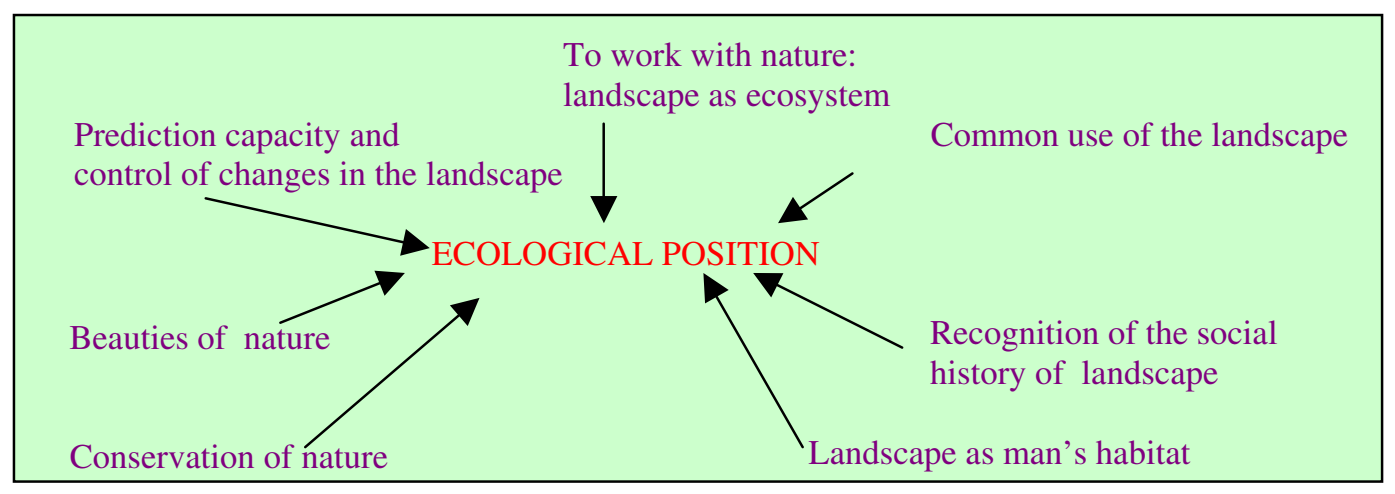

Figure 2: Aspects of the approach of landscape ecology. 


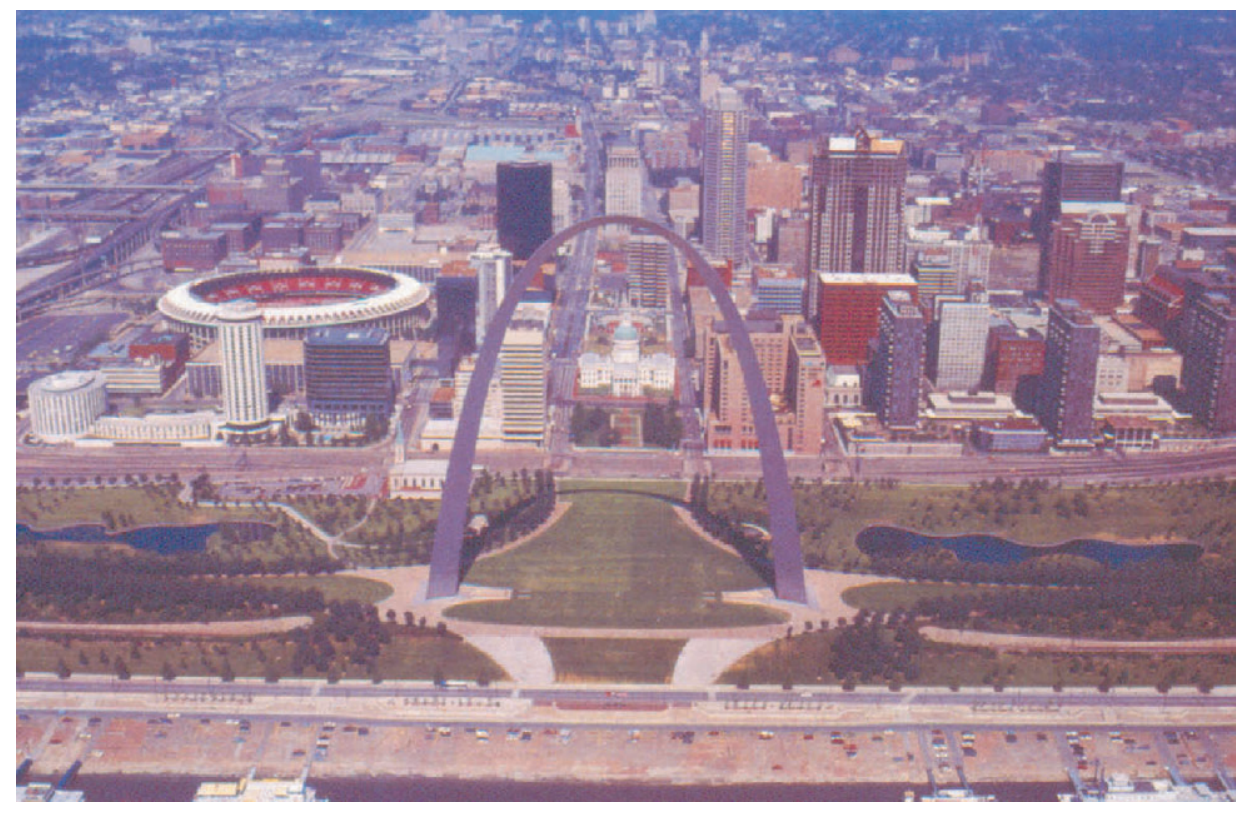

Figure 3: Periurban green belt in St. Louis (Missouri).

Box 12.C of the Döbrís Assessment [17] contains a summary of the concept of green planning in Europe. It states: 'Green Plans are general long-term strategies for the treatment of environmental problems through environmental considerations within the policies and programs of all the activity sectors'. There are several examples in Europe, and some others are now being implemented. Denmark, France, Ireland, Norway, Holland and the United Kingdom have adopted a green plan that establishes future objectives. The objectives are specified by topic (climatic change, acidification, etc.) and by sectors or groups (industry, agriculture, energy, consumers).

The implementation of a green plan requires the collaboration of all the sectors of society, based on new ways of participation and control of the mechanisms, and on the information about the situation of the environment.

Finally, let us mention some examples of green plans: Canada, Green Plan for all Canada; Denmark, Danish Government Plan of Action: Our Common Future; France, Green Plan of the Region of Île de France; Ireland, A Program of Environmental Action; Holland, Plan of National Environmental Policy and NEPP Plus; Norway, Report n 46 and Future is Now; United Kingdom, This Common Heritage; and the European Union, Towards Sustainability, Program V of Environmental Action.

\section{PHASES OF A GREEN PLAN: THE MODEL OF THE GREEN PLAN OF VALENCIA}

Green planning is implemented following a number of phases [18] (Fig. 4).

\subsection{Analysis}

The analysis phase divides the study topic into environmental analysis, analysis of ecology and city flows, and landscape analysis. 

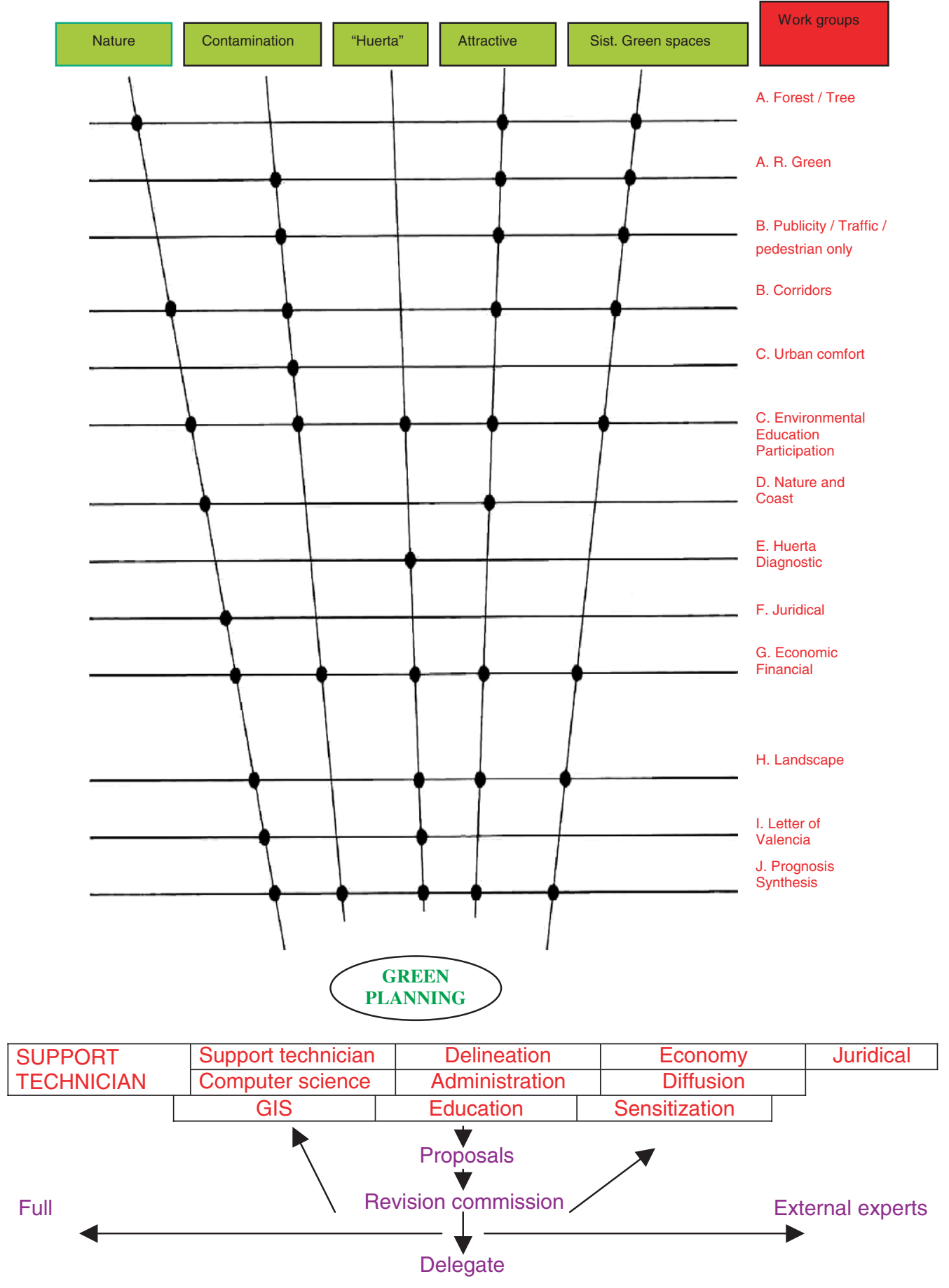

Figure 4: Organizational diagram of the Technical Office of the Green Plan of Valencia. 
Environmental analysis studies the different kinds of ground and water, the presence of trees and its relation with the city, other types of vegetation within the urban area, links between vegetation and microclimates, pollution, and urban comfort or 'discomfort'.

\subsection{Synthesis}

During the synthesis phase the territory is characterized. This territorial characterization is the result of the different inventories of the spaces. In the territorial characterization of some cities that have already developed their green plans, these inventories are classified into two groups: open spaces and built spaces. The former include the green zones (forests, parks, gardens, lawns, trees, crop fields, bushes, beaches and coast, etc.) and the latter include a wide range of possibilities with massive human intervention (anthropogenesis; massive constructions with and without green areas, family houses with courtyards and gardens, buildings, factories, etc.) and built areas of special interest (industrial areas, harbors, beaches, railway stations, etc.).

The most important city flows in the environmental analysis are energy, traffic and water. Ecology is analyzed in close relation with economy, indicating the balance between satisfaction of current human needs, future generations, and the savings and/or regeneration of finite or renewable resources. Far away is the so-called 'border economy' in which the flow of resources is considered inexhaustible.

Landscape is a concept that can be approached from many points of view and possibilities. We can distinguish different subsytems. One subsystem is the 'producer' of the landscape, which includes biotic, abiotic and human-based elements, with a flow of objects that form the subsystem of 'visible' landscape, and from this, through a perceptive filter, it flows towards the subsystem of the 'users'. The planning action affects the producer subsystem, and the information, legislation and myths affect the perceptive filter. With regard to the users' subsystem, it results in analyses, studies and management.

The best approach would be a comprehensive conception that included all the subsystems. The landscape and the environment offer a two-side possibility for the city: an esthetic aspect or a healthy character. In the urban medium, both considerations are of vital importance but the regulations are scarce.

In the analysis phase there is a great dispersion of efforts in the collection of information or in the sectoral studies. This analytical period leads to a disaggregated vision that can result in the loss of an overall vision. After the analysis, it is necessary to integrate all the information collected, and to homogenize the different approaches in order to elaborate the conclusions by the weighed aggregation of the information obtained during the analysis phase. This phase is called phase of synthesis-prognosis.

In this phase of synthesis it is fundamental to identify the system of green spaces, both urban and periurban, or spaces with a similar behavior. Orthogonal air photographs taken using a film sensitive to short infrared wavelengths allow the identification of 'soft' tissues, with low radiant re-radiation, and green areas, trees, crop fields and fruit trees, etc. (Fig. 5).

This teledetection allows us to locate the distribution of the green elements in the urban and periurban areas and facilitates correct urban planning. As an illustration, we can mention the Green Plan for the region of Île de France (Paris and surroundings). This plan distinguishes the so-called ecosystem of the urban region, which consists of the green grid of agglomeration, towards the city center, the green ring, the rural ring, and the valleys and green connections.

Landscape ecology covers the esthetic perspective and the health of the ecosystems. The landscape is a nonrenewable resource, of difficult access. With respect to the protection of land planning tools it is worth mentioning the ecological map developed in Barcelona [3]. The inventory of this city characterizes the territory using indicators similar to what has been done in Brussels, 


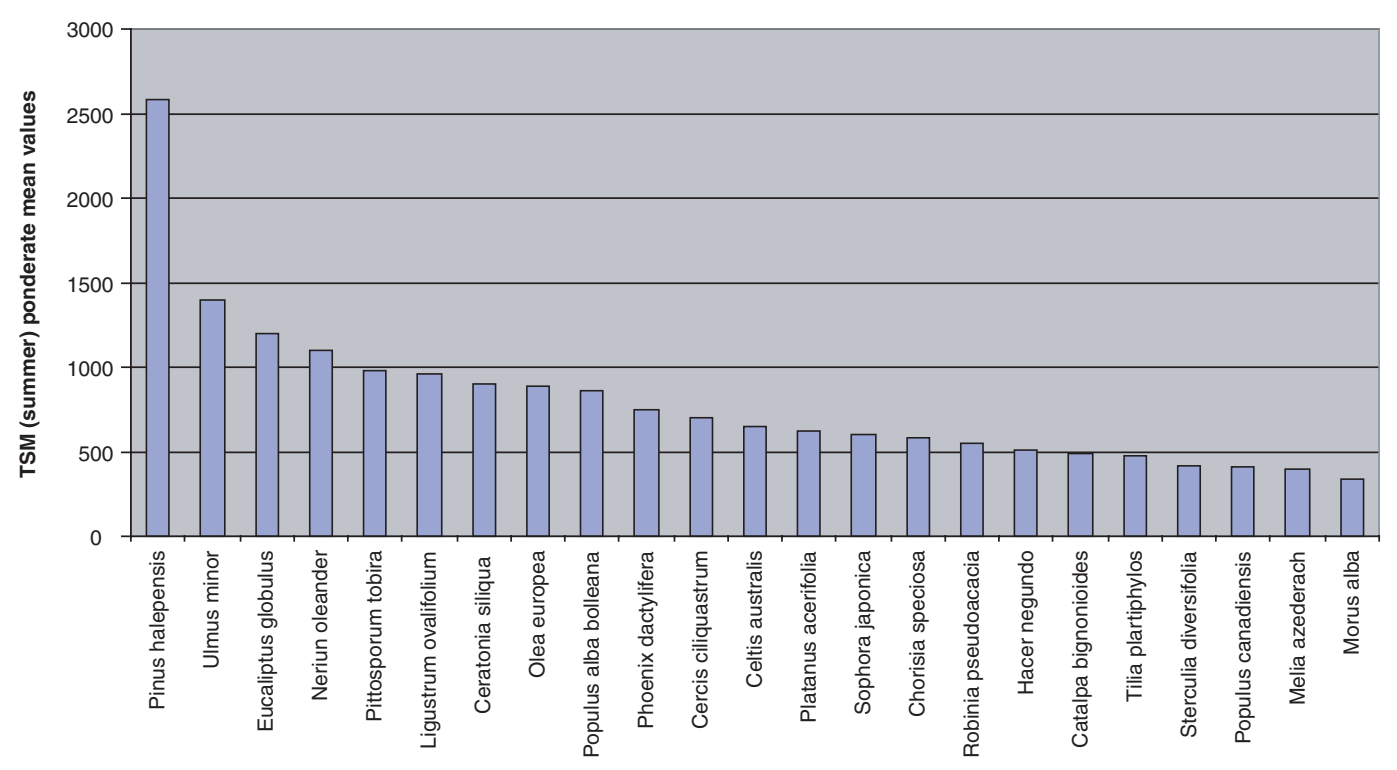

Figure 5: Classification of the species by the accumulation of total sedimentable matter (TSM). Preliminary study for the Green Plan of Valencia.

Île de France or Berlin. This study distinguishes between open and green areas [19], and the rings and rural areas and green connections.

The landscape is the external manifestation of the processes that take place in the territory. Its role is of integration and its analysis and valuation are fundamental when making decisions in a green plan. The landscape in land planning is approached from the perspective of the visual landscape. This analysis and valuation approach covers cultural landscapes, esthetics, human activities and agricultural landscapes.

The evaluation of the landscape is usually based on the work developed by a certain author [20], with his indirect method, singularity, quality, diversity, and on the psychological mechanisms of the observers: degree of naturality and integration of the anthropic elements introduced by man.

The approach that introduces nature in the city comes from the Saxon countries, but has extended to the southern countries, which are now also enjoying the wild side of the city, integrated and complemented by other urban activities. It is necessary, however, to plan the presence of nature in the city, adjusting its magnitude and needs, its geographical distribution, and its accessibility. The studies of synthesis incorporate the processing of information, the characterization of the medium, etc., for further diagnosis of the land plan.

An inventory is the main tool to obtain an overall vision of the situation. Hence, the inventory of nature in the city should determine the use of the places, the knowledge of the regulations, and the demands of the population and the existing natural habitats.

\subsection{Diagnosis}

After the integration and synthesis actions and prior to the development of the land plan comes the diagnosis. The data of both previous processes are matched to obtain an accurate and robust diagnosis. 
The diagnosis is a document with the capacity of convincing and with a short clear description of the objectives of the green plan. In parallel to the diagnosis, either before, after or simultaneously, it is important to know the solutions that can help understand the processes and that support the conclusions reached in the process.

There are many contributions on this subject by experts and researchers, as well as by some institutions, which have provided recommendations on this urban problem, in particular on the problems of the concentration of population in cities and megacities and on the problems of out-of-control cities.

In all these processes the communication between land planners and the public, whose lives and interests become affected by the actions of the land plan is of particular relevance. The exchange of ideas and information is not only a democratic requirement but it also clarifies and legitimizes the intentions of the project team.

\subsection{Planning}

After the diagnosis and the definition of the objectives of the plan, the next step consists of determining the possible actions to take, assessing them and selecting the most suitable solution to develop. At this step land planning progressively turns to management, identifying new problems depending on the option chosen and on the system's own dynamics, then restarting the process again in an iterative way.

For the development of a successful green plan, a number of operational principles are established, among which are: being proactive rather than reactive and visionary as well as pragmatic, informing and at the same time prescribing, clearly defining the properties and the mid- and long-term goals, being realistic with respect to political support and resources, considering compensating mechanisms for those citizens negatively affected by the changes, and coming to a political and public agreement to make the process operational. The process then goes on from planning to management; the management phase of the plan deals with the development and implementation of the objectives of the plan. The management of the plan is the reality.

\subsection{Management}

The green plan results from a management plan that includes a number of projects, an action plan, and the control of the results and changes. The management body-public, private or combined—must be an only entity to avoid conflicts among the different departments or units.

The management of the plan comprises different areas: environment and landscape, legal unit and regulations, finance, land use and activities, nature and wild life, communication and promotion (Fig. 6).

All these aspects usually overlap. However, because each of these aspects needs a different approach and analysis, it is important to define them stating clearly the responsibilities involved in their management to avoid confusion in the actions to be taken.

\section{GREEN ZONES IN THE CITY AND URBAN COMFORT}

Today there is clear evidence that the climatic conditions are different in cities and in their surroundings. A large majority of research work corroborates the fact that cities are situated in a highly transformed physical environment with a number of natural characteristics [21, 22, 23].

Basically the city center is warmer than its surroundings due to solar radiation. This topic has been extensively studied in the literature $[24,25]$. In addition, this effect is increased by the long 


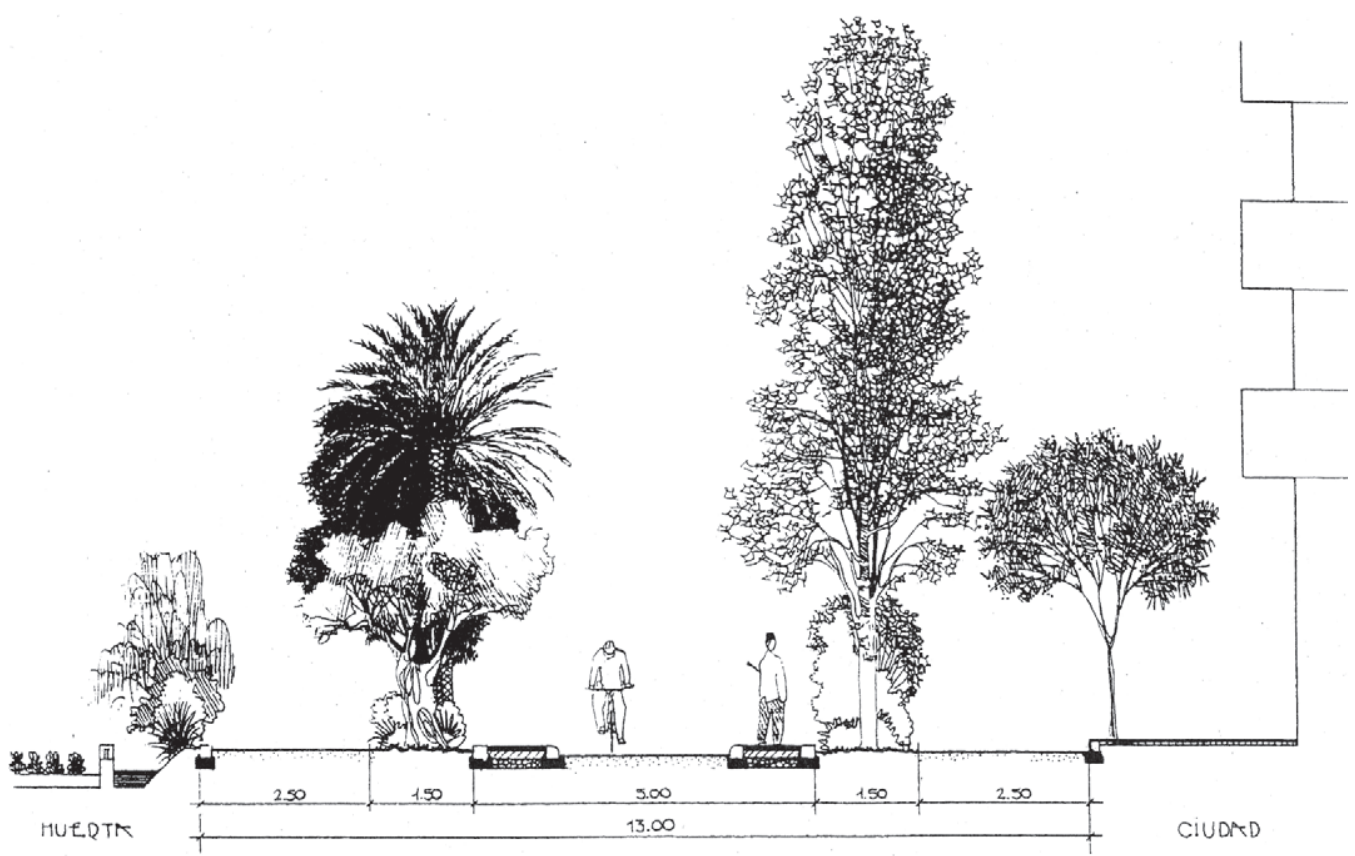

Figure 6: Proposal of a structure with trees and transition screens City-Market Garden for the Green Plan of Valencia.

wavelength radiation emitted by the surface and reemitted back to the ground due to the pollution layer covering cities. We also have to add the little evapotranspiration, the heat generated by the population and the weak winds blowing in cities as compared to the city surroundings. On the other hand, one of the basic roles of trees, especially in warm regions, is the control of luminosity and solar radiation, preventing it from reaching the paved surfaces that have a greater capacity for heat accumulation.

Although the role of trees in cities is the basis of an ecological approach to city planning, it has been neglected due to the uncontrollable and greedy development of cities in which the car is the king of the street.

From ancient times, as stated in some of the work by Hipocrates, man has tried to control thermal comfort in different ways. Recent climatic studies try to relate the different meteorological variables either graphically or mathematically to calculate the comfort range under different conditions.

In this work we analyze the meteorological variables that affect urban climate and that are used to calculate the different comfort indices. Next, we analyze the performance of the different comfort indices for the city of Valencia, comparing these indices with a real bioclimatic characterization of the city. Finally, following the criteria used by the authors of the comfort indices $[9,10]$, we relate these indices to the green zones in order to determine the influence of the green areas on urban microclimate, and as a consequence, on human comfort.

The main objective of this work is to obtain a suitable formulation of the comfort indices for the city of Valencia that allows the quantification of the green zones. In other words, we present a methodology that will allow urban planners to know the amount and the location of the green areas for a more comfortable city. 
The need to analyze comfort in terms of green zones is based on the well-known fact that the presence of vegetation in cities alters the energy budget of local climates, causing variations in the amount of solar radiation reaching the ground [11], in wind patterns, in the environmental temperature and in air humidity [12]. These effects make a significant contribution to improve human comfort in open urban spaces.

The other radiative properties of vegetation are albedo and transmissivity [26], as well as transmittance of visible light [27]. Similarly, many research studies have analyzed the effects of vegetation on the air temperature and humidity $[12,24]$.

\section{METHODOLOGY}

Although the first studies on climatic comfort date back to the 19th century, the most significant formulations on thermal comfort have been developed in the last few years. The goal of these bioclimatological research studies has been the quantification of thermal perception and the development of comfort ranges that allow estimating human response under certain climatic conditions.

The estimation of thermal comfort ranges consists of finding a balance between man, whose vital constants are well defined by his body's biological temperature, and the complex environmental variables that act on the human body since each of these environmental variables alter the effects of the other variables, i.e. they are interrelated and do not act independently of each other, as expressed in the conventional measurements.

The concept of comfort may be defined in different ways, though all of them are based on the criteria of energetic balance between the human body and the environment. The thermal balance of the human body consists of keeping the body's temperature between 36.5 and $37^{\circ} \mathrm{C}$. If this temperature increases or decreases it causes discomfort, and when it exceeds $40^{\circ} \mathrm{C}$ blood circulation problems appear, and above $41-42^{\circ} \mathrm{C}$ even coma or total collapse may occur.

The energetic balance is calculated using the following equation:

$$
0=M \pm R \pm C v \pm C d-E
$$

where $M$ represents the metabolic heat, $R$ the heat exchange by radiation, $C v$ the heat exchange by convection, $C d$ the heat exchange by conduction and $E$ the heat losses by evaporation.

The most significant climatic variables affecting thermal comfort are:

1. Air temperature in open spaces: It acts on all heat exchange processes in combination with clothing. Therefore, it is the most essential variable to define thermal comfort.

2. Humidity: It regulates evaporation and plays an important role at high temperatures.

3. Wind: It increases evaporation by convection.

4. Radiation: It is the main source of heat gain.

Comfort indices combine these variables to quantify the thermal comfort ranges for different spaces and conditions.

In this work we have used the following comfort indices: corrected effective temperature (TEC), Sipple and Passel's eolic cooling index (W), Hill's index (R), Hill's index adapted to the Iberian Peninsula (RAPI), Thom's index (ID), Vinje's index (PE), radiant temperature index (TMR), convective cooling index (C) and radiant heat exchange index (R), wet bulb global temperature (WBGT), Terjung's index, and Olgyay's bioclimatic chart [28]; all of them are well-known comfort indices for open spaces; other well-known indices such as PMV have not been used in this study. We have analyzed the behavior of these comfort indices for the city of Valencia and we have selected those indices best suited for the bioclimatic characterization of the city [29]. 
The scenario of study was the city of Valencia, with a warm sub-desert climate according to FAOUNESCO. It presents a wind pattern dominated by east-west breezes. The city is located on an alluvial plain surrounded by Market Garden with a specific local climate.

The most relevant climatic data of the city have been obtained from the Meteorological Local Service (Servicio Meteorológico Zonal de Levante), which catalogues Valencia as a city with a Mediterranean climate. This allows us to extend the application of this study to the Mediterranean area.

From the ecological point of view, the city of Valencia presents imbalances. The amount of green zones is scarce; its urban area occupies 13,465 ha with 782,846 inhabitants; at present the ratio of the green area is $3.16 \mathrm{~m}^{2} /$ inhabitant (Ayuntamiento de Valencia, 2003), which is far lower than the $9 \mathrm{~m}^{2} /$ inhabitant recommended by WHO for cities. However, it has 115,203 trees (year 2003) located in 1249 streets. This is a very positive factor for the control of solar radiation, which is very high in the summer, as it prevents solar radiation from reaching the paved surfaces that have a greater capacity for heat accumulation.

Samples were taken from eight districts of the city. The districts have been selected based on their representativity of the whole urban environment (Fig. 7). These eight districts include the two most densely populated districts ( 2 and 6 ), those districts with particular urban and environmental features in the outskirts of the city (4 and 10) and rural districts, the Market Garden (7, 17 and 19), and the seafront (11).

Samples were taken in each district to show the particular features of the urban space. For example, for each district the sampling points were located in streets with different orientations, different types of paving and spaces with different environmental values, with and without trees, with and without lawns, etc.
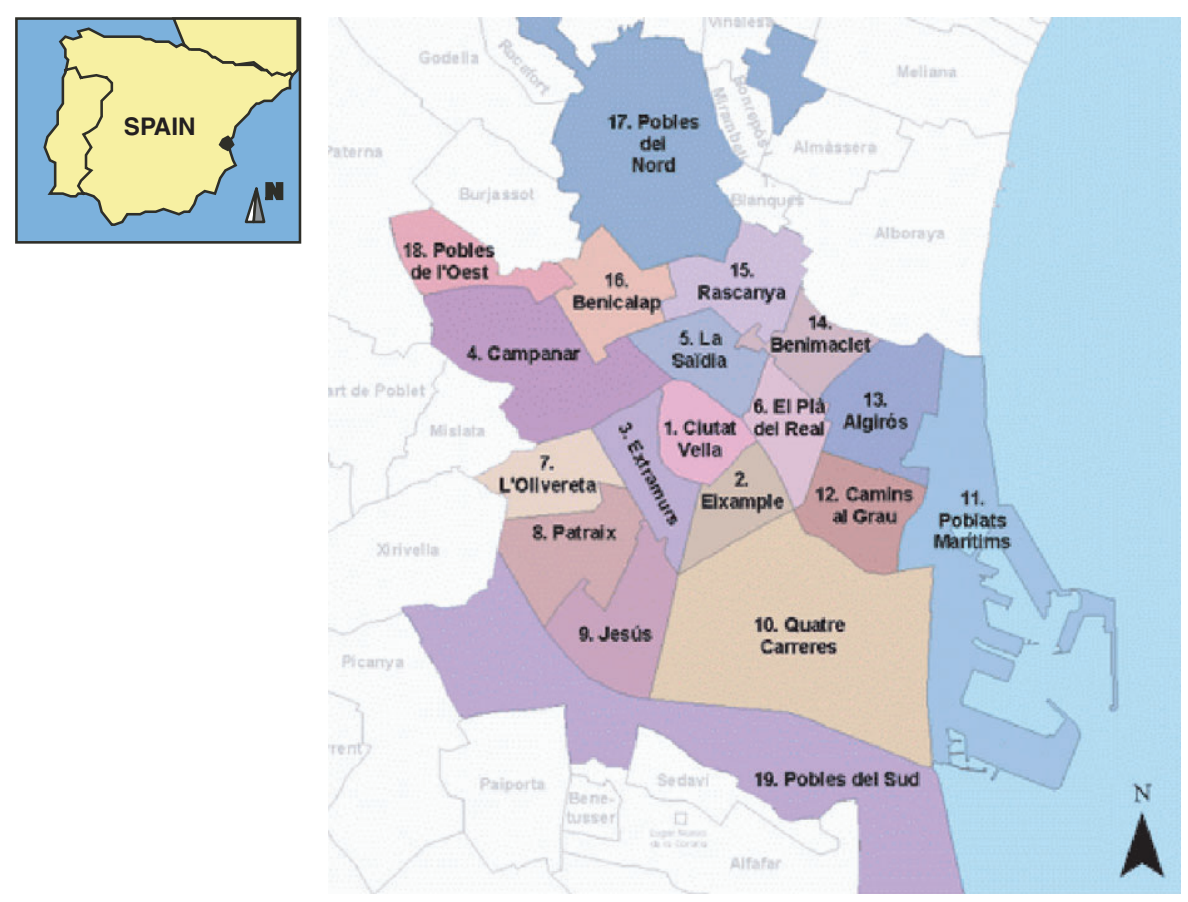

Figure 7: Map of Valencia city indicating the districts under study. 
An average of 18 sampling points were measured in each district. The number of samples per sampling point was 10, in keeping with the statistical model developed for this work.

The samples taken correspond to solar radiation, air temperature (dry and wet), ambient temperature and wind speed.

The samples for solar radiation and albedo were measured using a radiometer Pyranometer Sensor (LI-200SA), with a curve having a relative response percentage between 400 and $1100 \mathrm{~m}$. The recordings were always taken under the same meteorological conditions and clear skies.

Temperature was measured using a conventional aspiropsychrometer for the simultaneous recording of wet and dry air; the relative humidity was calculated using the dry and wet temperatures and the psychrometric tables.

The ambient temperature was measured with a 'black bulb thermometer' after 10 min of stationary recording. The temperature obtained is the combination of the air temperature, direct solar radiation and radiation by convection of the surroundings. In our case, this measurement was always taken at direct sun exposure. The other measurements were taken in the shade and by avoiding the influence of the surroundings; the recordings were taken at a distance of $2 \mathrm{~m}$ from any building and at least at $1 \mathrm{~m}$ above the ground level.

Wind speed was measured using a Clima Hies digital anemometer, with a recording range between 0.1 and $35 \mathrm{~m} \mathrm{seg}^{-1}, \pm 0.2 \%$ error and integration capacity for periods between 1 and $10 \mathrm{seg}$. The blades of the anemometer were located at heights of 1.8 and $2 \mathrm{~m}$ above the ground level and registering the measurement simultaneously to the black bulb thermometer.

\section{RESULTS}

The comfort indices selected for this work were ID, WBGT and PE (Vinje), as the behavior of these indices best matched the bioclimatic characterization of the city of Valencia.

The results of these comfort indices in terms of the green zones are shown in Table 2. As can be seen from Table 2, the determination coefficients are considerably high, much higher than the values obtained by other authors [10], with values of $0.35224 \%$.

This formulation has a special relevance in this work as it allowed the calculation of comfort as a function of the green zones in an urban space or district of the city. Subsequently we reformulated these comfort indices for the city of Valencia based on the analysis of linear regression, shown in Table 3.

Table 2: Formulation of the ID and WBGT comfort indices in terms of the relative amount of green areas for each city district.

\begin{tabular}{lll}
\hline Formulation of the index & $\begin{array}{l}\text { Correlation and determination } \\
\text { coefficients }\end{array}$ & Significance levels \\
\hline $\mathrm{ID}=68.3513-32.1545 \mathrm{~m}^{2}$ & $r=-0.8262$ & $(1-\alpha) \geq 90 \%$ \\
$\quad$ green area/ground] & $R^{2}=68.27 \%$ & \\
$\mathrm{ID}=\mathrm{e}^{\left(4.2246-0.48 \mathrm{~m}^{2}\right)}$ & $r=-0.8306$ & $(1-\alpha) \geq 90 \%$ \\
$\quad$ green area/ground] & $R^{2}=69.01 \%$ & $(1-\alpha) \geq 90 \%$ \\
WBGT $=72.5075-47.1822 \mathrm{~m}^{2}$ & $r=0.8337$ & \\
$\quad$ green area/ground] & $R^{2}=69.52 \%$ & $(1-\alpha) \geq 90 \%$ \\
WBGT $=\mathrm{e}^{\left(4.2837-0.6693 \mathrm{~m}^{2}\right)}$ & $r=-0.8401$ & \\
$\quad$ green area/ground] & $R^{2}=70.59 \%$ & \\
\hline
\end{tabular}


Table 3: Formulation of the ID and WBGT comfort indices in terms of the type of ground: 'soft ground' (B), 'hard ground' (D) and the time of the day (H).

\begin{tabular}{llll}
\hline Winter & ID $=6.7809 \mathrm{~B}+6.938 \mathrm{D}+0.648 \mathrm{H}$ & $\left(R^{2}=99.3\right)$ & {$[(1-\alpha) \geq 95 \%]$} \\
Summer & ID $=20.57 \mathrm{~B}+20.7277 \mathrm{D}+0.33 \mathrm{H}$ & $\left(R^{2}=99.7\right)$ & {$[(1-\alpha) \geq 95 \%]$} \\
Spring & ID $=15.60 \mathrm{~B}+15.48 \mathrm{D}+0.44 \mathrm{H}$ & $\left(R^{2}=99.0\right)$ & {$[(1-\alpha) \geq 95 \%]$} \\
Autumn & ID $=18.33 \mathrm{~B}+9.13 \mathrm{D}+0.59 \mathrm{H}$ & $\left(R^{2}=98.0\right)$ & {$[(1-\alpha) \geq 95 \%]$} \\
Winter & WBGT $=36.66 \mathrm{~B}+37.39 \mathrm{D}+1.73 \mathrm{H}$ & $\left(R^{2}=99.2\right)$ & {$[(1-\alpha) \geq 95 \%]$} \\
Summer & WBGT $=67.98 \mathrm{~B}+68.73 \mathrm{D}+1.03 \mathrm{H}$ & $\left(R^{2}=99.8\right)$ & {$[(1-\alpha) \geq 95 \%]$} \\
Spring & WBGT $=59.07 \mathrm{~B}+58.99 \mathrm{D}+1.16 \mathrm{H}$ & $\left(R^{2}=99.2\right)$ & {$[(1-\alpha) \geq 95 \%]$} \\
Autumn & WBGT $=38.29 \mathrm{~B}+39.07 \mathrm{D}+1.81 \mathrm{H}$ & $\left(R^{2}=99.0\right)$ & {$[(1-\alpha) \geq 95 \%]$} \\
\hline
\end{tabular}

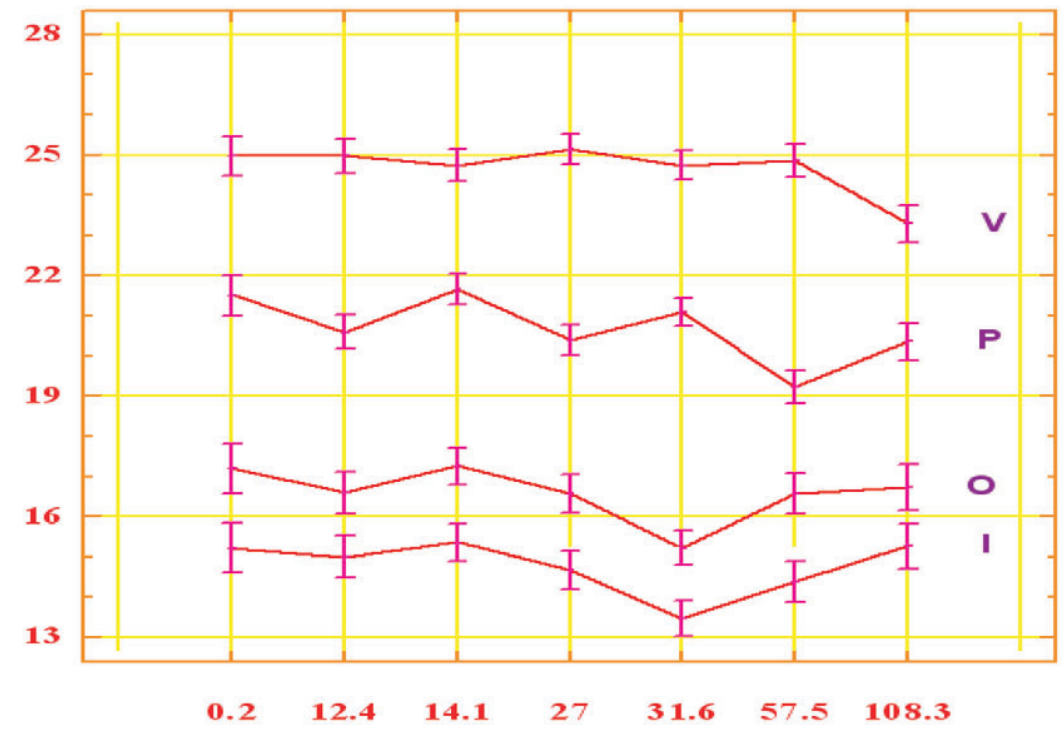

Figure 8: Behavior of the ID comfort index, for the different seasons of the year (the highest comfort value is 20.28). The values on the $y$-axis correspond to the amount of green zones for districts 19, 10, 4, 11, 2, 7 and 6 .

The formulation of the two comfort indices in Table 3 is based on B (soft ground), D (hard ground) and $\mathrm{H}$ (time of the day when the index was measured). The last factor was important since the meteorological measurements were recorded at the same time of the day in all the districts (in the time range between 10.00 a.m. and 2.30 p.m).

'Soft ground' refers to the surface areas covered with soil or lawn, green zones, streets with trees, well-oriented streets that permit the flow of winds during warm days, etc., while 'Hard ground' refers to paved surfaces, streets without trees, ill-oriented streets, etc.

The next step was to analyze the comfort indices as a function of the soft ground area for each season of the year (amount of green zone: $\mathrm{m}^{2} / 1000 \mathrm{~m}^{2}$ surface area) and for each district. The behavior of the different comfort indices is illustrated in Fig. 8. In this figure the $x$-axis represents the ID values and the $y$-axis represents the amount of green zones in the following districts: (19) Poblats del nort, (10) Quatre Carreres, (4) Campanar, (11) Marítim, (2) Eixample, (7) L'Olivereta and (6) Pla del Real. 
Table 4: Formulation of the ID, WBGT and VINJE comfort indices in terms of the type of ground: 'soft ground', 'hard ground' and green zones for each district.

\begin{tabular}{|c|c|c|}
\hline Type of ground & Hard & Soft \\
\hline \multicolumn{3}{|c|}{ ID index (adapted) } \\
\hline Spring & $\begin{array}{l}0.3294 \mathrm{~m}^{2} \text { green } / 1000 \mathrm{~m}^{2} \\
\text { surface area } R^{2}=54.65 \%\end{array}$ & $\begin{array}{l}0.3235 \mathrm{~m}^{2} \text { green } / 1000 \mathrm{~m}^{2} \\
\text { surface area } R^{2}=52.50 \%\end{array}$ \\
\hline Summer & $\begin{array}{l}0.3972 \mathrm{~m}^{2} \text { green } / 1000 \mathrm{~m}^{2} \\
\text { surface area } R^{2}=55.28 \%\end{array}$ & $\begin{array}{l}0.3825 \mathrm{~m}^{2} \text { green } / 1000 \mathrm{~m}^{2} \\
\text { surface area } R^{2}=52.85 \%\end{array}$ \\
\hline Autumn & $\begin{array}{l}0.2699 \mathrm{~m}^{2} \text { green } / 1000 \mathrm{~m}^{2} \\
\text { surface area } R^{2}=56.46 \%\end{array}$ & $\begin{array}{l}0.2579 \mathrm{~m}^{2} \text { green } / 1000 \mathrm{~m}^{2} \\
\text { surface area } R^{2}=53.93 \%\end{array}$ \\
\hline Winter & $\begin{array}{l}0.2402 \mathrm{~m}^{2} \text { green } / 1000 \mathrm{~m}^{2} \\
\text { surface area } R^{2}=56.44 \%\end{array}$ & $\begin{array}{l}0.2307 \mathrm{~m}^{2} \text { green } / 1000 \mathrm{~m}^{2} \\
\text { surface area } R^{2}=54.55 \%\end{array}$ \\
\hline \multicolumn{3}{|c|}{ WBGT index (adapted) } \\
\hline Spring & $\begin{array}{l}0.1644 \mathrm{~m}^{2} \text { green } / 1000 \mathrm{~m}^{2} \\
\text { surface area } R^{2}=55.57 \%\end{array}$ & $\begin{array}{l}1.1369 \mathrm{~m}^{2} \text { green } / 1000 \mathrm{~m}^{2} \\
\text { surface area } R^{2}=53.48 \%\end{array}$ \\
\hline Summer & $\begin{array}{l}0.2987 \mathrm{~m}^{2} \text { green } / 1000 \mathrm{~m}^{2} \\
\text { surface area } R^{2}=54.44 \%\end{array}$ & $\begin{array}{l}1.2503 \mathrm{~m}^{2} \text { green } / 1000 \mathrm{~m}^{2} \\
\text { surface area } R^{2}=54.23 \%\end{array}$ \\
\hline Autumn & $\begin{array}{l}0.9969 \mathrm{~m}^{2} \text { green } / 1000 \mathrm{~m}^{2} \\
\text { surface area } R^{2}=56.45 \%\end{array}$ & $\begin{array}{l}0.9586 \mathrm{~m}^{2} \text { green } / 1000 \mathrm{~m}^{2} \\
\text { surface area } R^{2}=54.09 \%\end{array}$ \\
\hline Winter & $\begin{array}{l}0.9499 \mathrm{~m}^{2} \text { green } / 1000 \mathrm{~m}^{2} \\
\text { surface area } R^{2}=56.74 \%\end{array}$ & $\begin{array}{l}0.9121 \mathrm{~m}^{2} \text { green } / 1000 \mathrm{~m}^{2} \\
\text { surface area } R^{2}=54.71 \%\end{array}$ \\
\hline \multicolumn{3}{|c|}{ VINJE index (adapted) } \\
\hline Spring & $\begin{array}{l}0.1334 \mathrm{~m}^{2} \text { green } / 1000 \mathrm{~m}^{2} \\
\text { surface area } R^{2}=56.50 \%\end{array}$ & $\begin{array}{l}0.1181 \mathrm{~m}^{2} \text { green } / 1000 \mathrm{~m}^{2} \\
\text { surface area } R^{2}=44.53 \%\end{array}$ \\
\hline Summer & $\begin{array}{l}0.0758 \mathrm{~m}^{2} \text { green } / 1000 \mathrm{~m}^{2} \\
\text { surface area } R^{2}=48.79 \%\end{array}$ & $\begin{array}{l}0.0721 \mathrm{~m}^{2} \text { green } / 1000 \mathrm{~m}^{2} \\
\text { surface area } R^{2}=44.52 \%\end{array}$ \\
\hline Autumn & $\begin{array}{l}0.1255 \mathrm{~m}^{2} \text { green } / 1000 \mathrm{~m}^{2} \\
\text { surface area } R^{2}=58.44 \%\end{array}$ & $\begin{array}{l}0.1124 \mathrm{~m}^{2} \text { green } / 1000 \mathrm{~m}^{2} \\
\text { surface area } R^{2}=52.39 \%\end{array}$ \\
\hline Winter & $\begin{array}{l}0.1610 \mathrm{~m}^{2} \text { green } / 1000 \mathrm{~m}^{2} \\
\text { surface area } R^{2}=48.03 \%\end{array}$ & $\begin{array}{l}0.1488 \mathrm{~m}^{2} \text { green } / 1000 \mathrm{~m}^{2} \\
\text { surface area } R^{2}=46.91 \%\end{array}$ \\
\hline
\end{tabular}

Significance levels $(1-\alpha) \geq 92 \%$.

From this figure we can observe that district (6) Pla del Real, with the greatest amount of green zones (108.3), is the district best positioned in the comfort range during all seasons of the year. In this figure, the seasons are represented by: V (Summer), I (Winter), O (Autumn) P (Spring).

Figure 8 shows that in district 6 the summer comfort curve (V) goes down, the spring comfort curve slightly goes up, and the autumn (O) and winter (I) comfort curves go up, getting closer to the comfort range values; i.e. for all seasons of the year the green zones have a smoothing effect on the thermal conditions (decreasing the temperature during summer and increasing the temperature during autumn and winter).

This diagram corroborates our initial hypothesis, but only for the district with the greatest amount of green zones. The reason for this may be found in the explanations given by other authors [30]: for the green zones to modify the local climatic conditions significantly it is necessary to have a large green area. For this reason, we have extended the concept of green zones to the widest concept of 'soft ground'. 
Therefore, the sampling measurements were extended to an average of 10 measurements per sampling point. This offers a number of advantages from a statistical point of view. The greater amount of data available allowed us to obtain more accurate results. This led us to reformulate the three comfort indices best suited for the city of Valencia, namely ID, WBGT and VINJE, based on the new concept of green zones (i.e. based on the broader concept of soft ground or hard ground). The results are shown in Table 4.

We believe that the formulation of the comfort indices for each season of the year and for each type of ground (soft or hard), based on the amount of green zones (per $1000 \mathrm{~m}^{2}$ of surface area), will provide a more accurate approach for the quantification of green zones in cities. The statistical determination is better than that for Seoul and higher than 50\% in all cases, which makes it a reliable tool for the calculation of the comfort index as a function of the green zones.

These formulations of the comfort indices allow the estimation of the amount of green zones necessary in a city district to make it comfortable. It is only requirement is to replace B or D with the percentage of soft or hard ground in the district. Then, we establish the maximum and minimum values of ID and obtain the amount of green zones $\mathrm{m}^{2} / 1000 \mathrm{~m}^{2}$ surface area.

\section{CONCLUSIONS}

In this work, first, we present a historical overview of the concept of green planning, and we analyze the role played by the green zones in the city of Valencia (Spain). Next, the different phases involved in green planning are described comparing the results obtained for the city of Valencia with other results found in the literature.

Large fields of investigation exist, opened for every city on all those aspects that constitute the physical way and that have been outlined in the 'analysis' phase of green planning: fauna, vegetation, landscape, water resources, forest studies, physical way, physical environment, legal studies, infrastructure and transportation, energy consumption, pollution, etc.

Other important social factors such as human ecology should be analyzed from the sociological point of view. There are also important factors related to the economy and social expenses generated by environmental aspects.

One of the main aspects of a green plan is the study of the green zones. The second part of this paper is devoted to the analysis of green zones in cities and their effects on human comfort.

The city of Valencia has been used as the scenario for this research work. Different measurements and sample analysis have been performed including the most important environmental variables used to calculate comfort values.

Ten different comfort indices were selected from the literature, and the three most representative comfort indices for the city of Valencia were selected for this research work to analyze the effect of the vegetation in the different districts of the city.

The results obtained in the different districts show the different behavior of the city areas depending on the amount of green zones existing in each district, which demonstrates the direct correlation between urban comfort and green zones.

In this work we present a new formulation that permits the quantification of the green zones in a city, based on the measurement of the climatic conditions and statistical analysis. This formulation provides an important tool for green zone planning in cities since the formulations of the comfort indices proposed in this work allow the calculation of surface area required for a district to be considered as comfortable.

The possibilities offered by this new formulation permit the design of sustainable cities, since green zones constitute one of the most accurate indicators of sustainability. 


\section{ACKNOWLEDGEMENTS}

We would like to thank the $\mathrm{R}+\mathrm{D}+\mathrm{i}$ Linguistic Assistance Office at the Polytechnic University of Valencia for their help in revising this paper.

\section{REFERENCES}

[1] United Nations, Inform on the population, Department of Social and Economic Matters, Secretariat of the United Nations, 2002.

[2] Niemeyer, O., The city of the year 2000, mail from the UNESCO, March 1985.

[3] Terradas, J., Urban Ecology, Ed. Rubes: Barcelona, 2001.

[4] Expert Group on the Urban Environment, Towards more sustainable urban land use, Advice to the European Commission for Policy and Action, Brussels, 2001.

[5] Sukopp, H. \& Werner, P., Nature in Cities, Council of Europe: Strasbourg, 1982.

[6] Givoni, B., Urban design for different climates, World Meteorological Organization, TD-No. 346, 1989.

[7] Gómez, F., Gaja, E. \& Reig,A. Vegetation and climatic changes in a city. Ecological Engineering, 10(4), pp. 355-360, 1998.

[8] Spiller, M., Roof gardens and green façades for the improvement of urban environments, Thesis B.L. Arch, University of NSW, 1993.

[9] Salvador, P.J. \& Smith, D.R., Vegetation and urban climate in Valencia, Spain, a pilot project, MaB-UNESCO, pp. 125, 1987.

[10] Kwi-Gon Kim, Climate, urbanization and green spaces in urban areas, the case of Seoul, MaB-UNESCO, University of Seoul, 1989.

[11] Terjung, W.H. \& O'Rourque, P.A., Relative influence of vegetation on urban energy budgets and surface temperatures. Boundary-Layer Meteorology, 21, pp. 255-263, 1981.

[12] Horbert, M. \& Kirchgeorg, A., Climatic and air hygienic aspects in the planning of inter-city open spaces: Berliner grosser tiergarten. Energy and Buildings, 5(1), pp. 11-22, 1982.

[13] COM (90), Green Paper on the Environment, Communication from the Commission to the Council and Parliament Commission of the European Communities, COM (90) 218, Brussels, 27 June 1990.

[14] EU Expert Group on the Urban Environment, European Sustainable Cities, First Report, Brussels, 1994.

[15] Breheny, M., Planning for environmental capacity: the case of historic towns. International Symposium on Urban Planning and the Environment, Seattle 1994.

[16] Tagliolini, A., Storia del giardino italiano, Ponte a le Grazie: Florence, 1994.

[17] Döbrís Assessment, Europe's Environment, eds. D. Stanner \& P. Bourdeau, European Environment Agency: Copenhagen, 1995.

[18] Salvador, P., The green planning in the cities. Landscape's Architecture, No. 123, June-July 2004.

[19] Duvigneaud, P., La Syntèse Écologique, Doin Éditeurs: Paris, 1974.

[20] Iaurif, J., La Charte de l'Ille de France, Les Cahiers de l'IAURIF, 97/98, París, 1991.

[21] Höppe, P., Aspects of human biometeorology in past, present and future. International Journal of Biometeorology, 40(1), pp. 19-23, 1997.

[22] Jauregui, E., The last Ms for 40th anniversary issue. Aspects of urban human biometeorology. International Journal of Biometeorology, 40(1), pp. 58-61, 1997.

[23] Unger, J., Comparisons of urban and rural bioclimatological conditions in the case of a CentralEuropean city. International Journal of Biometeorology, 43(3), pp. 139-144, 1999.

[24] Oke, T.R., Boundary Layer Climates, 2nd edn, Routledge: London, 1990. 
[25] Bansal, N.K., Hauser, G. \& Minke, G., Passive Building Design, A Handbook of Natural Climatic Control, Elsevier Science B.V.: Amsterdam, 1994.

[26] Canton, M.A., Cortegoso, J.L. \& Rosa de L., Solar permeability of urban trees in cities of western Argentina. Energy and Buildings, 20(3), pp. 219-230, 1994.

[27] Brown, R. \& Gillespie, T., Microclimatic Landscape Design: Creating Thermal Comfort And Energy Efficiency, John Wiley and Sons: New York, 1995.

[28] Gómez, F., Gil, L. \& Jabaloyes, J., Experimental investigation on the thermal comfort in the city: relationship with the green areas, interaction with the urban microclimate. Building and Environment, 39(9), pp. 1077-1086, 2004.

[29] Gómez, F., Tamarit, N. \& Jabaloyes, J., Bioclimatic characterization of the Mediterranean city: the Valencian case. PLEA '99, ed. S. Szokolay, PLEA: Brisbane, pp. 807-812, 1999.

[30] Sthülpnagel, A., Klimatische Veränderungen in Ballunngsgebieten unter besonderer Berüchschtingug der Ausgleichaswirkung von Grünflächen, dargestellt am Beispiel von Berlin (West), Diss. FB 14, TU, Berlin, 1987. 